\title{
Potencial do soro de leite líquido como agente encapsulante de Bifidobacterium Bb-12 por spray drying: comparação com goma arábica
}

\author{
Potential of liquid whey as the encapsulating agent of Bifidobacterium Bb-12 by spray drying: \\ comparison with arabic gum
}

\author{
Fabiane Picinin de Castro-Cislaghi ${ }^{{ }^{*}}$ Carlise Beddin Fritzen-Freire ${ }^{\mathrm{II}}$ \\ Ernani Sebastião Sant'Anna ${ }^{\text {II }}$
}

\section{RESUMO}

O objetivo do trabalho foi avaliar o potencial do soro de leite líquido como agente encapsulante de Bifidobacterium Bb-12 por spray drying, comparando-o com a goma arábica, a qual é tradicionalmente utilizada na tecnologia de microencapsulação. Foram determinados o rendimento da microencapsulação e a viabilidade das microcápsulas durante o armazenamento. Quando o soro de leite foi utilizado como agente encapsulante, o rendimento da microencapsulação foi maior e a viabilidade das células manteve-se elevada e constante durante doze semanas. O soro de leite apresentou-se como um eficiente agente encapsulante de Bifidobacterium por spray drying.

Palavras-chave: microencapsulação, Bifidobacterium, probiótico, soro de leite, atomização, secagem, goma acácia.

\section{ABSTRACT}

The objective of this study was to evaluate the potential of liquid whey as the encapsulating agent Bifidobacterium $B b-12$ by spray drying, compared with arabic gum, which is typically used in microencapsulation technology. The microencapsulation yield and viability during storage were determined. When the whey was used as the encapsulating agent, the microencapsulation yield was higher, and cell viability remained high and steady for twelve weeks. The whey was shown to be an effective encapsulating agent of Bifidobacterium by spray drying.

Keywords: microencapsulation, Bifidobacterium, probiotic, whey, spray drying, drying, acacia gum.

\section{INTRODUÇÃO}

A microencapsulação é um processo no qual as células são retidas dentro de uma matriz ou membrana encapsulante (ANAL \& SINGH, 2007). Entre as várias aplicações dessa tecnologia, na indústria de alimentos, a principal aplicação envolve a proteção de compostos biologicamente ativos ou células, como as bactérias probióticas, em ambientes nocivos para eficiente liberação nos locais alvo (DOHERTY et al., 2011). Probióticos são microrganismos vivos que, quando administrados em quantidades adequadas, conferem benefícios à saúde do indivíduo (FAO/WHO, 2002). Para que um alimento seja considerado probiótico, recomenda-se que contenha no mínimo $10^{6}$ $10^{7} \mathrm{UFC}^{-1}$ do produto (FAO/WHO, 2002; SHAH, 2007).

Entre todas as gomas usadas na microencapsulação, a goma arábica destaca-se devido às suas excelentes propriedades de emulsificação e, portanto, tem sido amplamente utilizada (DICKINSON, 2003). No entanto, o elevado custo, o suprimento limitado e variações na qualidade têm restringido o uso dessa goma como material de parede na microencapsulação e incentivado a busca por materiais encapsulantes alternativos (GHARSALLAOUI et al., 2007).

\footnotetext{
'Universidade Tecnológica Federal do Paraná (UTFPR), Linha Santa Bárbara, s/n, 85601-970, CP 135, Francisco Beltrão, PR, Brasil. E-mail: fabianecastro@utfpr.edu.br. Autor para correspondência.

"Departamento de Ciência e Tecnologia de Alimentos, Centro de Ciências Agrárias, Universidade Federal de Santa Catarina (UFSC), Florianópolis, SC, Brasil.
} 
O soro de leite é o líquido residual obtido a partir da coagulação do leite destinado à fabricação de queijos ou de caseína (BRASIL, 2005). É um subproduto de relevante importância na indústria de laticínios, tendo em vista o volume produzido e sua composição (HUFFMAN, 1996). No entanto, apesar do seu valor nutricional, grande parte do soro de leite produzido ainda é descartada indevidamente no solo e em rios, causando sérios problemas de poluição ambiental, devido a sua alta Demanda Bioquímica de Oxigênio (DBO) (SILVA \& BOLINI, 2006). Portanto, alternativas tecnológicas para o seu adequado aproveitamento são fundamentais. As proteínas do soro na forma de concentrado proteico de soro (CPS) ou ainda isolado proteico de soro (IPS) têm sido usadas na microencapsulação de probióticos (PICOT \& LACROIX, 2004; REID et al., 2007; RODRÍGUEZHUEZO et al., 2007; DOHERTY et al., 2011; GBASSI et al., 2011). No entanto, o uso de soro de leite na forma líquida foi estudado somente por PIMENTELGONZÁLEZ et al. (2009), que empregaram o soro doce concentrado como emulsificante na microencapsulação de Lactobacillus rhamnosus por emulsificação. Até o momento, não existem publicações sobre o uso de soro de leite líquido como agente encapsulante de probióticos por spray drying. Visando à ampliação da utilização desse subproduto na indústria de alimentos, o objetivo deste trabalho foi avaliar o potencial do soro de leite líquido como agente encapsulante de Bifidobacterium Bb-12 por spray drying, comparandoo com a goma arábica, a qual é tradicionalmente utilizada na tecnologia de microencapsulação.

\section{MATERIAL E MÉTODOS}

Para armazenamento em longo prazo, culturas liofilizadas de Bifidobacterium animalis subsp. lactis Bb-12 (Chr. Hansen) foram mantidas na proporção de 2,5g $100 \mathrm{~mL}^{-1}$ de uma solução estéril de leite desnatado reconstituído $12 \%$ a $-18^{\circ} \mathrm{C}$ (cultura estoque). Antes da microencapsulação, a cultura foi ativada em estufa a $37^{\circ} \mathrm{C}$ por $2 \mathrm{~h}$. O soro de leite foi obtido a partir da coagulação enzimática de leite pasteurizado padronizado, através da adição de quimosina $\left(0,9 \mathrm{~mL} \mathrm{~L} \mathrm{~L}^{-1}\right.$, Chr. Hansen $\left.{ }^{\circledR}\right)$ e solução de Cloreto de Cálcio $40 \%(\mathrm{~m} / \mathrm{v})\left(0,4 \mathrm{~mL} \mathrm{~L}^{-1}\right)$ e subsequente incubação a $37^{\circ} \mathrm{C}$ por 40 minutos. O soro foi coletado após a quebra do coágulo e dessora, de acordo com metodologia de FURTADO \& NETO (1994). Bifidobacterium Bb-12 foi microencapsulada pelo método de spray drying, empregando dois agentes encapsulantes: goma arábica $\left(10 \mathrm{~g} 100 \mathrm{~mL}^{-1}\right)$ e soro de leite líquido. $\mathrm{O}$ agente encapsulante foi previamente preparado e autoclavado a $121^{\circ} \mathrm{C}$ por $15 \mathrm{~min}$. Posteriormente, a cultura estoque foi misturada ao agente encapsulante para obter a solução de alimentação do spray dryer. As microcápsulas foram obtidas em um spray dryer co-corrente, de escala laboratorial (B-290 mini spray dryer, Buchi), à temperatura de entrada constante de $150^{\circ} \mathrm{C}$ e temperatura de saída de $55 \pm 3^{\circ} \mathrm{C}$. A solução de alimentação contendo Bifidobacterium Bb-12 foi mantida sob agitação à temperatura ambiente e alimentada para a câmara de secagem através de uma bomba peristáltica, com fluxo de alimentação de $6 \mathrm{~mL}$ $\min ^{-1}$, fluxo do ar de secagem de $35 \mathrm{~m}^{3} \mathrm{~h}^{-1}$ e pressão do compressor de ar de $0,7 \mathrm{MPa}$. O pó obtido (microcápsulas) foi coletado da base do ciclone e armazenado em frascos estéreis hermeticamente fechados.

Para enumeração de Bifidobacterium Bb12, utilizou-se ágar MRS (Difco, Sparks, MD, EUA) modificado com a adição de $0,2 \%(\mathrm{~m} / \mathrm{v})$ de Cloreto de Lítio e 0,3\% (m/v) de Propionato de Sódio (MRS-LP) (VINDEROLA; REINHEIMER, 2000), pela técnica de semeadura em profundidade (Pour plate). Após incubação a $37^{\circ} \mathrm{C}$ por 72 horas em jarras anaeróbicas contendo AnaeroGen ${ }^{\circledR}$ (Oxoid), foi realizada a contagem de células viáveis, expressa em log de unidade formadora de colônia por mL ou g (log UFC mL $\mathrm{mb}^{-1} \mathrm{ou} \mathrm{g}^{-1}$ ). Entretanto, os microrganismos encapsulados foram primeiramente liberados das microcápsulas de acordo com metodologia de KIM et al. (2008), com modificações, homogeneizando $0,1 \mathrm{~g}$ das microcápsulas em 9,9mL de tampão fosfato $(0,1 \mathrm{M}, \mathrm{pH} 7,0)$ por 10 minutos, usando uma barra magnética.

O rendimento da microencapsulação (Encapsulation Yield - EY) foi calculado através da fórmula: $\mathrm{EY}=\left(\mathrm{N} / \mathrm{N}_{\mathrm{o}}\right) \times 100$, em que $\mathrm{N}_{\mathrm{o}}$ é o número de células viáveis na solução de alimentação do spray dryer e N é o número de células viáveis no pó obtido, ambos expressos em log UFC g-1 (PICOT; LACROIX, 2004). O rendimento é uma medida combinada da eficiência da tecnologia de microencapsulação e da sobrevivência das células viáveis durante o processo (ANNAN et al., 2008). Foi avaliada a viabilidade de Bifidobacterium $\mathrm{Bb}-12$ microencapsulada durante o armazenamento. A umidade das microcápsulas foi determinada por secagem em estufa a $105^{\circ} \mathrm{C}$, de acordo com metodologia da AOAC (2005).

Os dados foram submetidos à análise de variância (ANOVA), usando o software Statistica 7.0, seguida pelo teste de Tukey para comparação das médias, com nível de significância de 5\%, quando encontradas diferenças significativas entre os tratamentos. Todas as análises foram realizadas em 
triplicata e os dados expressos como média \pm desvio padrão.

\section{RESULTADOS E DISCUSSÃO}

Na tabela 1, é possível observar que não houve diferença $(\mathrm{P}>0,05)$ entre as contagens de células viáveis nas soluções de alimentação do spray dryer preparadas com goma arábica ou com soro de leite, ou seja, a contagem inicial antes do processo de microencapsulação foi a mesma para ambos os agentes encapsulantes. Entretanto, após spray drying, houve maior redução da viabilidade de Bifidobacterium Bb12 microencapsulada com goma arábica, resultando em uma menor contagem de células viáveis no pó obtido, quando comparada à bactéria microencapsulada em soro de leite. Portanto, o rendimento da microencapsulação foi maior quando o soro de leite foi utilizado como agente encapsulante.

Os rendimentos obtidos neste estudo para a microencapsulação tanto com soro de leite

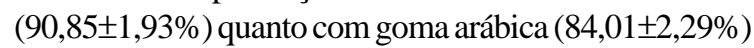
foram satisfatórios, quando comparados a outros trabalhos. CHÁVARRI et al. (2010) microencapsularam B. bifidum e Lactobacillus gasseri com alginato e quitosana por extrusão e observaram rendimentos de 19,5 a 40,2\%. Em estudo realizado por ZHAO et al. (2008), houve uma redução de 1,2-2,4 log na viabilidade de $\boldsymbol{L}$. acidophilus após a microencapsulação por spray drying com ß-ciclodextrina e goma acácia. CHAN et al. (2011) observaram uma redução de 4log na viabilidade de microcápsulas liofilizadas de $\boldsymbol{L}$. casei, obtidas por extrusão com alginato. Quando foi adicionado amido ao alginato, observaram uma redução de 1,5-2log UFC $\mathrm{g}^{-1}$. Segundo GOLOWCZYC et al. (2010), a habilidade para sobreviver ao spray drying varia consideravelmente entre as espécies de microrganismos. LIAN, HSIAO \& CHOU (2002), ao microencapsular Bifidobacterium por spray drying à temperatura de saída constante, verificaram que a sobrevivência das células ao processo depende da cepa e do agente encapsulante utilizados. PICOT \& LACROIX (2004) observaram que o rendimento da microencapsulação, além de ser dependente da cepa e agente encapsulante, também é influenciado pelo método empregado. Quando Bifidobacterium foi microencapsulada em uma solução de WPI por spray drying, o rendimento foi maior do que quando microencapsulada pelo método de emulsificação seguido de spray drying, com WPI e gordura do leite.

Segundo KIM \& BHOWMIK (1990), a temperatura de saída no spray dryer é o principal parâmetro que afeta a viabilidade bacteriana. SUNNYROBERTS \& KNORR (2009) relataram que a sobrevivência de L. rhamnosus após spray drying foi inversamente proporcional à temperatura de saída. Visto que, neste estudo, foi utilizada uma única cepa de microrganismo e selecionados os mesmos parâmetros no spray dryer, pode-se sugerir que as diferenças observadas, quanto ao rendimento da microencapsulação e viabilidade nas microcápsulas obtidas, são devido aos diferentes agentes encapsulantes empregados. O soro de leite apresentou melhores resultados quando comparado à goma arábica.

O conteúdo de água de pós probióticos é um fator crítico que influencia a estabilidade da bactéria durante o armazenamento (WANG et al., 2004; SANTIVARANGKNA et al., 2007; MENG et al., 2008; CHAN et al., 2011). Os valores de umidade foram similares $(\mathrm{P}>0,05)$ para as microcápsulas obtidas com ambos agentes encapsulantes: $4,90 \%( \pm 0,84)$ para goma arábica e 3,05\% $( \pm 0,43)$ para soro de leite. Segundo GARDINER et al. (2000) e MENG et al. (2008), é necessária uma umidade residual de $4 \%$ ou menos para

Tabela 1 - Contagem de células viáveis de Bifidobacterium Bb-12 na solução de alimentação e pó obtido após spray drying, redução da viabilidade e rendimento da microencapsulação (EY).

\begin{tabular}{lll}
\hline & \multicolumn{2}{c}{ Gonte encapsulante--oro de leite } \\
\hline Solução de alimentação $\left(\log \mathrm{UFC} \mathrm{g}^{-1}\right)$ & Goma arábica & Soro \\
Pó (log UFC g $\left.{ }^{-1}\right)$ & $10,13^{\mathrm{a}} \pm 0,26$ & $10,28^{\mathrm{a}} \pm 0,10$ \\
Redução da viabilidade ${ }^{*}\left(\log \mathrm{UFC} \mathrm{g}^{-1}\right)$ & $8,50^{\mathrm{a}} \pm 0,12$ & $9,34^{\mathrm{b}} \pm 0,16$ \\
EY $(\%)$ & $1,62^{\mathrm{a}} \pm 0,27$ & $0,94^{\mathrm{b}} \pm 0,20$ \\
\hline
\end{tabular}

\footnotetext{
* diferença entre a contagem de células viáveis $\left(\log U F C \mathrm{~g}^{-1}\right)$ na solução de alimentação e no pó obtido após spray drying.

** resultados expressos como média \pm desvio padrão $(n=3)$.

*** letras diferentes na mesma linha indicam diferença significativa entre as médias pelo teste de Tukey $(\mathrm{P}<0,05)$.
} 
o armazenamento prolongado de pós contendo probióticos. ZAYED \& ROOS (2004) observaram que o conteúdo ótimo de água para armazenamento de $\boldsymbol{L}$. salivarius subsp. salivarius variou de 2,8 a 5,6\%, enquanto que valores maiores de água residual imediatamente após a secagem levam a perdas mais elevadas de células probióticas durante o armazenamento na forma de pó. O conteúdo de água residual obtido neste estudo para as microcápsulas de Bifidobacterium Bb-12 com goma arábica e com soro de leite é adequado para armazenamento a longo prazo.

A fim de avaliar o efeito da temperatura de armazenamento na viabilidade de Bifidobacterium Bb12 microencapsulada com goma arábica, os pós obtidos no spray dryer foram mantidos a $4^{\circ} \mathrm{C}$ e a $-18^{\circ} \mathrm{C}$. As microcápsulas mantidas a $-18^{\circ} \mathrm{C}$ apresentaram contagens satisfatórias ( $>6 \log$ UFC g ${ }^{-1}$ ) durante 40 semanas (Figura 1). Entretanto, a viabilidade das microcápsulas armazenadas a $4{ }^{\circ} \mathrm{C}$ manteve-se adequada somente até a $28^{\mathrm{a}}$ semana de armazenamento. Resultados similares foram obtidos por SU et al. (2007), que observaram manutenção da viabilidade de $\boldsymbol{L}$. acidophilus e B. longum microencapsulados por spray drying, com maltodextrina e goma arábica, acima de 7log UFC g ${ }^{-1}$ durante cinco semanas de armazenamento a $4^{\circ} \mathrm{C}$. SIMPSON et al. (2005) avaliaram a viabilidade de
12 espécies de Bifidobacterium microencapsuladas por spray drying, com leite desnatado reconstituído com e sem adição de goma arábica, e relataram que todas apresentaram contagens de células viáveis $>6 \log$ UFC g ${ }^{-1}$ após 90 dias a $4^{\circ} \mathrm{C}$. Em estudo realizado por LORENZ (2009), a viabilidade de $\mathbf{L}$. acidophilus La-5 microencapsulado por spray drying com alginato de sódio foi $>6 \log \mathrm{UFC} \mathrm{g}^{-1}$ após 12 semanas a $-18^{\circ} \mathrm{C}$.

Apesar da redução na contagem de células viáveis observada nas microcápsulas com goma arábica mantidas a $4^{\circ} \mathrm{C}$, pode-se inferir que o período pelo qual a viabilidade manteve-se adequada é satisfatório, portanto o pó obtido com soro de leite como agente encapsulante foi armazenado nessa temperatura. As contagens de células viáveis nos pós obtidos após spray drying com soro de leite durante o armazenamento a $4^{\circ} \mathrm{C}$ mostraram que a viabilidade de

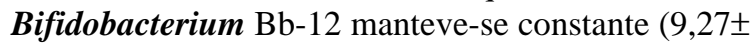
0,03log UFC g $\left.{ }^{-1}\right)(\mathrm{P}>0,05)$ ao final da $12^{\mathrm{a}}$ semana (Figura 2). Quando a goma arábica foi utilizada como agente encapsulante, foi observada uma redução de $1,18 \pm 0,16 \log$ UFC $\mathrm{g}^{-1}(\mathrm{P}<0,05)$ na viabilidade das microcápsulas armazenadas à mesma temperatura, por igual período. Em estudos realizados por RODRÍGUEZHUEZO et al. (2007) e ZHAO et al. (2008), houve uma redução de 1,32 e 1,0log UFC mL $\mathrm{mL}^{-1}$, respectivamente,

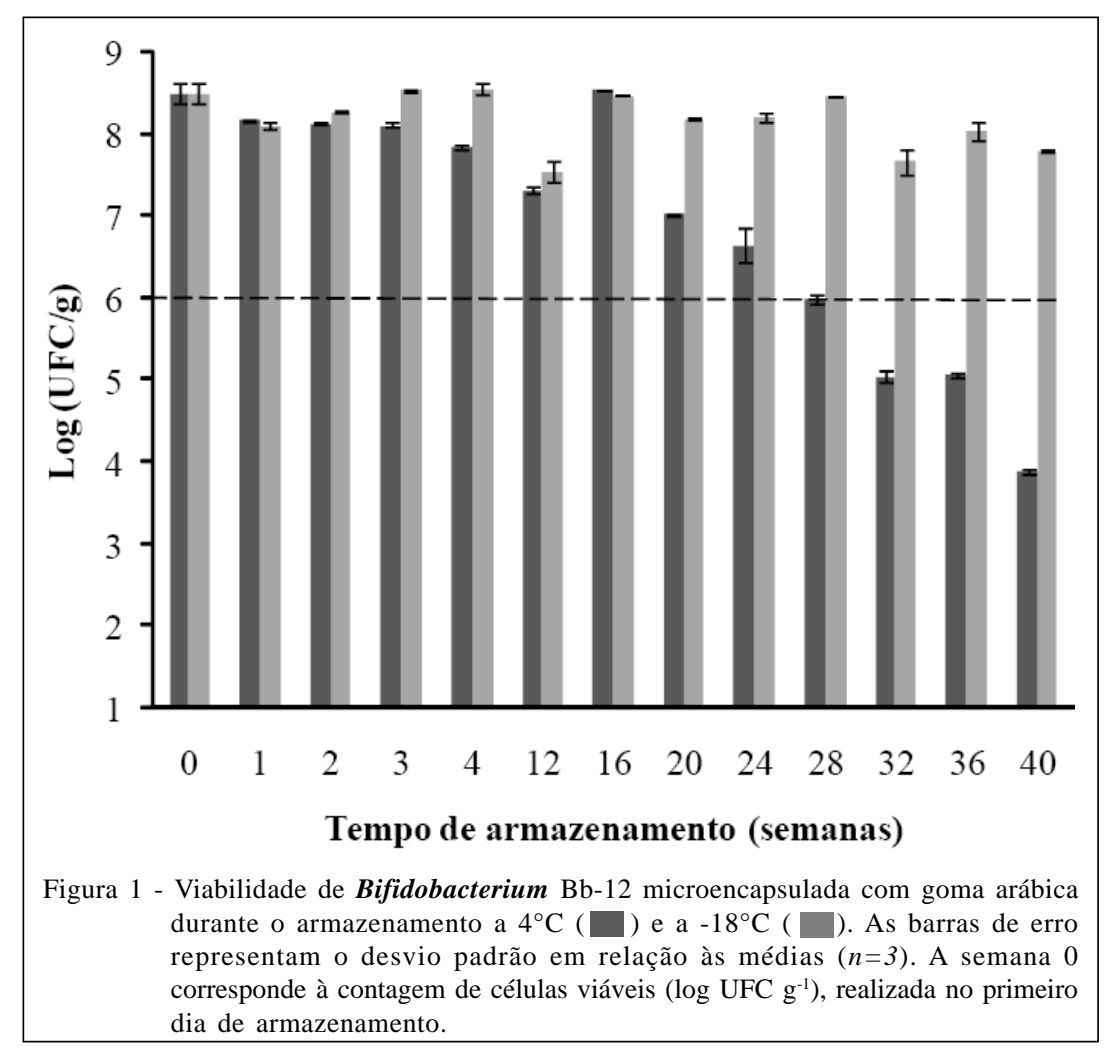

Ciência Rural, v.42, n.9, set, 2012. 


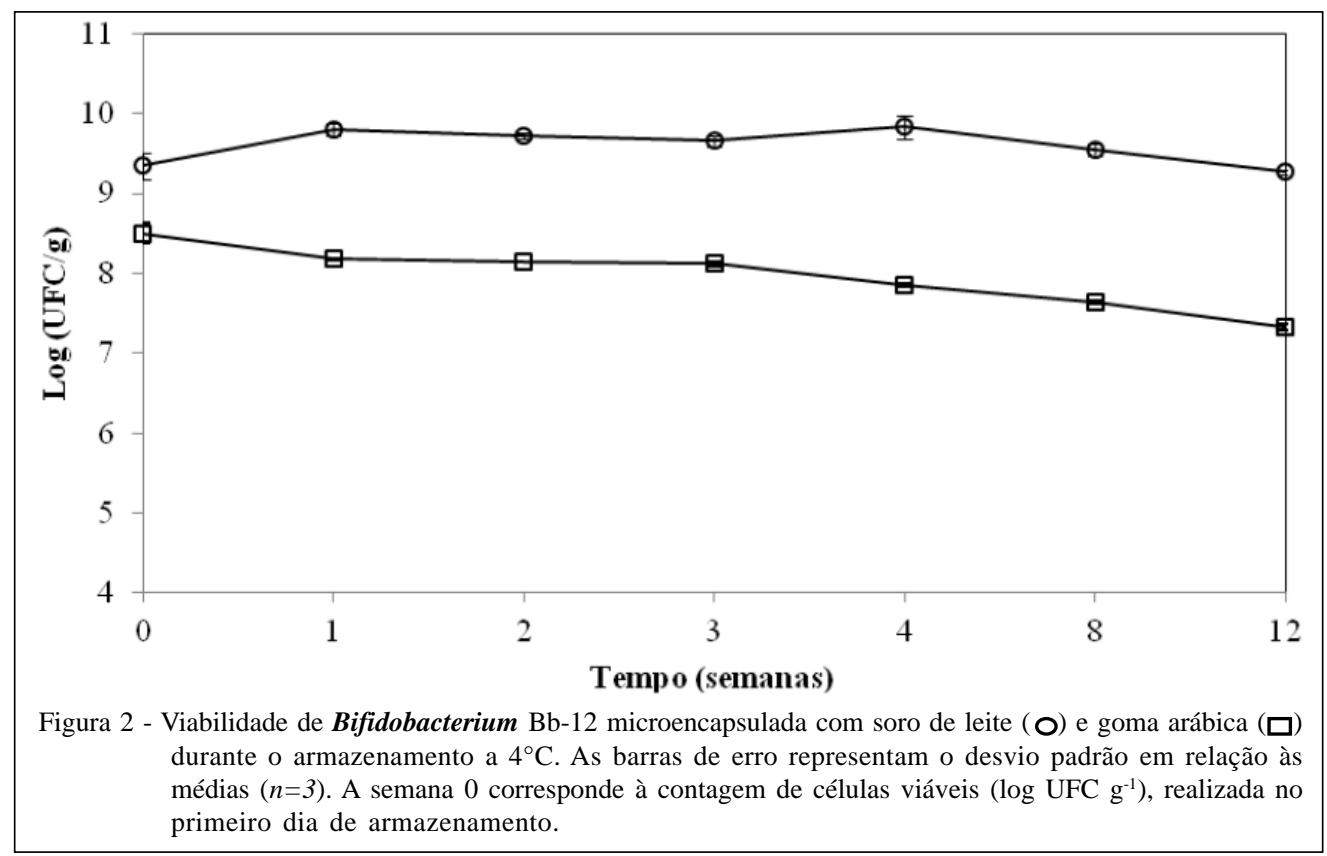

na viabilidade das células microencapsuladas por spray drying, armazenadas a $4^{\circ} \mathrm{C}$. A microencapsulação de Bifidobacterium $\mathrm{Bb}-12$ por spray drying com soro de leite, aplicada neste trabalho, mostrou-se como uma técnica eficaz na manutenção da viabilidade das células durante $\mathrm{o}$ armazenamento.

\section{CONCLUSÃO}

O soro de leite mostrou-se eficiente como agente encapsulante de Bifidobacterium Bb-12, quando comparado à goma arábica. Dessa forma, é possível empregar o soro de leite líquido na tecnologia de microencapsulação de probióticos, o que contribui para sua maior utilização, redução do desperdício e da poluição ambiental.

\section{AGRADECIMENTOS}

À Coordenação de Aperfeiçoamento de Pessoal de Nível Superior (CAPES) e ao Conselho Nacional de Desenvolvimento Científico e Tecnológico (CNPq), pelo financiamento do projeto e pela concessão de bolsa.

\section{REFERÊNCIAS}

ANAL, A.K.; SINGH, H. Recent advances in microencapsulation of probiotics for industrial applications and targeted delivery. Trends in Food Science \& Technology, v.18, p.240-251, 2007. Disponível em: <http://dx.doi.org/ 10.1016/j.tifs.2007.01.004>. Acesso em: 24 nov. 2011. doi: 10.1016/j.tifs.2007.01.004.
ANNAN, N.T. et al. Encapsulation in alginate-coated gelatin microspheres improves survival of the probiotic Bifidobacterium adolescentis 15703T during exposure to simulated gastrointestinal conditions. Food Research International, v.41, p.184-193, 2008. Disponível em: <http://dx.doi.org/10.1016/ j.foodres.2007.11.001>. Acesso em: 24 nov. 2011. doi: 10.1016/j.foodres.2007.11.001.

AOAC (Association of Official Analytical Chemists). Official methods of analysis of the association analytical chemists. 18.ed. Gaithersburg, MD, 2005. 1526p.

BRASIL. Ministério da Agricultura, Pecuária e Abastecimento. Instrução Normativa n.16, de 23 de agosto de 2005. Regulamento Técnico de Identidade e Qualidade de Bebida Láctea. Diário Oficial da União, Brasília, DF, 24 agosto 2005, sec.1, p.7.

CHAN, E.S. et al. Effects of starch filler on the physical properties of lyophilized calcium-alginate beads and the viability of encapsulated cells. Carbohydrate Polymers, v.83, p.225232, 2011. Disponível em: <http://dx.doi.org/10.1016/ j.carbpol.2010.07.044>. Acesso em: 24 nov. 2011. doi: 10.1016/j.carbpol.2010.07.044.

CHÁVARRI, M. et al. Microencapsulation of a probiotic and prebiotic in alginate-chitosan capsules improves survival in simulated gastro-intestinal conditions. International Journal of Food Microbiology, v.142, p.185-189, 2010. Disponível em: $<$ http://dx.doi.org/10.1016/j.ijfoodmicro.2010.06.022>. Acesso em: 24 nov. 2011. doi: 10.1016/j.ijfoodmicro.2010.06.022.

DICKINSON, E. Hydrocolloids at interfaces and the influence on the properties of dispersed systems. Food Hydrocolloids, v.17, p.25-39, 2003.

DOHERTY, S.B. et al. Development and characterisation of whey protein micro-beads as potential matrices for probiotic protection. 
Food Hydrocolloids, v.25, p.1604-1617, 2011. Disponível em: <http://dx.doi.org/10.1016/j.foodhyd.2010.12.012>. Acesso em: 12 out. 2011. doi: 10.1016/j.foodhyd.2010.12.012.

FAO/WHO. Guidelines for the evaluation of probiotics in food. 2002. Food and Agriculture Organization of the United Nations and World Health Organization Working Group Report. Disponível em: <http://www.fao.org/es/ESN/food/foodandfood_probio_en.stm>. Acesso em: 21 jul. 2011.

FURTADO, M.M.; NETO, J.P.M. Tecnologia de queijosmanual técnico para produção industrial de queijos. São Paulo: Dipemar, 1994. 118p.

GARDINER, G.E. et al. Comparative survival rates of humanderived probiotic Lactobacillus paracasei and L-salivarius strains during heat treatment and spray drying. Applied and Environmental Microbiology, v.66, p.2605-2612, 2000. Disponível em: <http://aem.asm.org/content/66/6/2605.short>. Acesso em: 02 mar. 2012. doi: 10.1128/?AEM.66.6.26052612.2000.

GBASSI, G.K. et al. In vitro effects of $\mathrm{pH}$, bile salts and enzymes on the release and viability of encapsulated Lactobacillus plantarum strains in a gastrointestinal tract model. International Dairy Journal, v.21, p.97-102, 2011. Disponível em: <http://dx.doi.org/ 10.1016/j.idairyj.2010.09.006>. Acesso em: 12 out. 2011. doi: 10.1016/j.idairyj.2010.09.006.

GHARSALLAOUI, A. et al. Applications of spray drying in microencapsulation of food ingredients: an overview. Food Research International, v.40, p.1107-1121, 2007. Disponível em: <http://dx.doi.org/10.1016/j.foodres.2007.07.004>. Acesso em: 12 out. 2011. doi: 10.1016/j.foodres.2007.07.004.

GOLOWCZYC, M.A. et al. Preservation of probiotic strains isolated from kefir by spray drying. Letters in Applied Microbiology, v.50, p.7-12, 2010.

HUFFMAN, L.M. Processing whey protein for use as a food ingredient. Food Technology, v.50, p.49-52, 1996.

KIM, S.J. et al. Effect of microencapsulation on viability and other characteristics in Lactobacillus acidophilus ATCC 43121. LWT - Food Science and Technology, v.41, p.493-500, 2008 Disponível em: <http://dx.doi.org/10.1016/j.lwt.2007.03.025>. Acesso em: 08 out. 2011. doi: 10.1016/j.lwt.2007.03.025.

KIM, S.S.; BHOWMIK, S.R. Survival of lactic acid bacteria during spray drying of plain yoghurt. Journal of Food Science, v.55, p.1008-1010, 1990.

LIAN, W.C. et al. Survival of bifidobacteria after spray-drying. International Journal of Food Microbiology, v.74, p.7986, 2002.

LORENZ, J.G. Comparação dos métodos de emulsificação e spray drying na microencapsulação de Lactobacillus acidophilus (La-5) e aplicação em sorvete. 2009. $85 \mathrm{f}$. Dissertação (Mestrado em Ciência dos Alimentos) - Programa de Pós-graduação em Ciência dos Alimentos, Universidade Federal de Santa Catarina, Florianópolis, SC.

MENG, X.C. et al. Anhydrobiotics: the challenges of drying probiotic cultures. Food Chemistry, v.106, p.1406-1416, 2008 .
PICOT, A.; LACROIX, C. Encapsulation of bifidobacteria in whey protein-based microcapsules and survival in simulated gastrointestinal conditions and in yoghurt. International Dairy Journal, v.14, p.505-515, 2004. Disponível em: <http:/ /dx.doi.org/10.1016/j.idairyj.2003.10.008>. Acesso em: 08 out. 2011. doi: 10.1016/j.idairyj.2003.10.008.

PIMENTEL-GONZÁLEZ, D.J. et al. Encapsulation of Lactobacillus rhamnosus in double emulsions formulated with sweet whey as emulsifier and survival in simulated gastrointestinal conditions. Food Research International, v.42, p.292-297, 2009. Disponível em: <http://dx.doi.org/10.1016/j.foodres.2008.12.002>. Acesso em: 10 jul. 2011. doi: 10.1016/j.foodres.2008.12.002.

REID, A.A. et al. Survival in food systems of Lactobacillus rhamnosus R011 microentrapped in whey protein gel particles. Journal of Food Science, v.72, p.M31-M37, 2007.

RODRÍGUEZ-HUEZO, M.E. et al. Pre-selection of protective colloids for enhanced viability of Bifidobacterium bifidum following spray-drying and storage, and evaluation of aguamiel as thermoprotective prebiotic. Food Research International, v.40, p.1299-1306, 2007.

SANTIVARANGKNA, C. et al. Damage of cell envelope of Lactobacillus helveticus during vacuum drying. Journal of Applied Microbiology, v.102, p.748-756, 2007. Disponível em: <http://onlinelibrary.wiley.com/doi/10.1111/j.13652672.2006.03123.x/pdf $>$. Acesso em: 02 mar. 2012. doi: 10.1111/j.1365-2672.2006.03123.x/pdf.

SHAH, N.P. Functional cultures and health benefits. International Dairy Journal, v.17, p.1262-1277, 2007. Disponível em: <http://dx.doi.org/10.1016/j.idairyj.2007.01.014>. Acesso em: 10 jul. 2011. doi: 10.1016/j.idairyj.2007.01.014

SILVA, K.; BOLINI, H.M.A. Avaliação sensorial de sorvete formulado com produto de soro ácido de leite bovino. Ciência e Tecnologia de Alimentos, v.26, p.116-122, 2006. Disponível em: <http://dx.doi.org/10.1590/S0101-20612006000100020>. Acesso em: 08 jul. 2011. doi: 10.1590/S010120612006000100020 .

SIMPSON, P.J. et al. Intrinsic tolerance of Bifidobacterium species to heat and oxygen and survival following spray drying and storage. Journal of Applied Microbiology, v.99, p.493501, 2005

SU, L.C. et al. Development of an Oriental-style dairy product coagulated by microcapsules containing probiotics and filtrates from fermented rice. International Journal of Dairy Technology, v.60, p.49-54, 2007.

SUNNY-ROBERTS, E.O.; KNORR, D. The protective effect of monosodium glutamate on survival of Lactobacillus rhamnosus GG and Lactobacillus rhamnosus E-97800 (E800) strains during spray-drying and storage in trehalose-containing powders. International Dairy Journal, v.19, p.209214, 2009.

VINDEROLA, C.G.; REINHEIMER, J.A. Enumeration of Lactobacillus casei in the presence of $\mathbf{L}$. acidophilus, bifidobacteria and lactic starter bacteria in fermented dairy 
products. International Dairy Journal, v.10, p.271-275, 2000. Disponível em: <http://dx.doi.org/10.1016/S09586946(00)00045-5>. Acesso em: 02 jul. 2011. doi: 10.1016/ S0958-6946(00)00045-5.

WANG, Y.-C. et al. Viability of latic acid bacteria and bifidobacteria in fermented soymilk after drying, subsequent rehydration and storage. International Journal of Food Microbiology, v.93, p.209-217, 2004. Disponível em: <http:/ /dx.doi.org/10.1016/j.ijfoodmicro.2003.12.001>. Acesso em: 02 mar. 2012. doi: 10.1016/j.ijfoodmicro.2003.12.001.
ZAYED, G.; ROOS, Y.H. Influence of trehalose and moisture content on survival of Lactobacillus salivarius subjected to freeze-drying and storage. Process Biochemistry, v.39, p.1081-1086, 2004.

ZHAO, R. et al. Measurement of particle diameter of Lactobacillus acidophilus microcapsule by spray drying and analysis on its microstructure. World Journal of Microbiology and Biotechnology, v.24, p.1349-1354, 2008. Disponível em: <http:/ /www.springerlink.com/content/8603742w7m651743/>. Acesso em: 02 jul. 2011. doi: 10.1007/s11274-007-9615-0. 